\title{
Dentatorubral Pallidoluysian Atrophy (DRPLA)-A Rare Neurological Disorder
}

\author{
MA HANNAN ${ }^{\mathrm{a}}$, MN ISLAM ${ }^{\mathrm{b}}$, A BEGUM $^{\mathrm{C}}$, ME JAHAN $^{\mathrm{d}}$
}

\begin{abstract}
:
Dentatorubral pallidoluysian atrophy (DRPLA) is a rare type of an autosomal dominant progressive late onset cerebellar ataxia. It is caused by a defect in a gene [CAG repeat in atrophin-1 (ATN1) on chromosome 12] and results in damage to the cerebellum, and to its connections within the central nervous system. It is also known as Haw River Syndrome and Naito-Oyanagi disease. This disorder seems to be very rare except in Japan. Patients with DRPLA can exhibit a variety of psychiatric symptoms in addition to extrapyramidal and cerebellar symptoms. We report a case
\end{abstract}

\section{Introduction:}

Dentatorubral-pallidoluysian atrophy (DRPLA) is a neurodegenerative disorder characterized by an unstable CAG trinucleotide repeat in the DRPLA gene on chromosome 12q12, leading to pathological changes in the brain. ${ }^{1,2}$ The human genome contains two atrophin genes; DRPLA has been correlated to the expansion of the polyglutamine region of the atrophin-1 gene on chromosome $12 \mathrm{p} 13.3^{3}$. A normal number of CAG repeats in the atrophin-1 gene is 7-34. Affected individuals display $49-93$ repeats ${ }^{4}$. Usually, patients with large expansions have an early onset and a rapid disease progression $^{1}$. DRPLA is a rare condition with an estimated prevalence of $0.2-0.7 / 100,000^{5}$ population in Japan. There is significant reduction in CNS tissue throughout the brain and spinal cord, with brain weights of DRPLA patients often becoming less than $1000 \mathrm{~g}^{6}$.

In regions lacking obvious neuronal depletion, atrophy of the neuropil is noted. The globus pallidus and

\footnotetext{
a. Dr. MA Hannan, FCPS (Medicine), MD (Neurology).

b. Dr. Md. Nazrul Islam, MCPS (Medicine), MD (Neurology Thesis part);

c. Dr. Ayesha Begum, DCP, M.Phil (Virology).

d. Dr. Mst. Effat Jahan, MPhil (Anatomy -Thesis part).

Address of Correspondence: Dr. M.A Hannan, Professor, Department of Neurology, Room No. 514, $4^{\text {th }}$ floor, Block-"C". Bangabandhu Sheikh Mujib Medical University, Shahbag, Dhaka. Received: 2 November, 2010

Accepted: 20 September, 2011
}

who was 28 years old unmarried man presented at BSMMU, Dhaka in 2010. The present work highlights the variable mode of presentation of DRPLA and the difficulty of an early diagnosis without facility of genetic analysis. The aim of our report was to describe typical clinical presentations of the disease without positive family history. Our patient presented with unsteadiness during walking, irrelevant behavior and talking, incontinence of urine and stool with occasional myoclonic seizure and dementia.

(J Bangladesh Coll Phys Surg 2012; 30: 48-52)

subthalamic nucleus demonstrate consistent neuronal loss and astrocytic gliosis. In general, the pallidoluysian degeneration is more severe than the dentatorubral degeneration in juvenile-onset and the reverse is true for the late adult-onset ${ }^{7}$. Patients with DRPLA manifest various combinations of symptoms such as epileptic seizures, myoclonus, ataxia, dementia ${ }^{8,9}$ and psychiatric symptoms ${ }^{10-12}$. There are two forms of DRPLA- the juvenile and adult forms ${ }^{7}$, In juvenile onset patients, particularly under the age of 30years, it tends to present with a progressive myoclonic epilepsy-picture with more marked dementia than is seen in patients with Huntington's Disease. In patients with adult onset typically above the age of 30years, DRPLA typically presents with a milder phenotype with ataxia, mild chorea and milder cognitive impairment ${ }^{13}$. Diagnosis of DRPLA rests on positive family history, clinical findings, and genetic testing. Family history can be difficult to obtain if a relative was misdiagnosed, died young, or experiences late onset of symptoms. Here we report the patient with DRPLA of juvenile onset which could not confirmed by genetic identification.

\section{Case history}

A 28 years-old ex-smoker, right handed, nondiabetic, nonhypertensive, unmarried male from Comilla, Bangladesh, reported us with the complaints of unsteadiness during walking for 8 years, irrelevant behavior and talking for 2years, incontinence of urine 
and stool for the same duration. According to the statement of mother of the patient he was reasonably well 8years back. Since then he developed progressive unsteadiness during walking. At the same time she also noticed sudden, involuntary, jerky movement of head followed by fall without loss of consciousness. For this reason they consulted several consultants and got some sort of relief. But from November 2007, he experienced many episodes of seizure. The seizure was generalized with loss of conciousness, lasted for several minutes, associated with incontinence of urine and stool. He also developed difficulty in swallowing which was more for liquid, poverty of speech, forgetfulness and abnormal posture of limbs. His speech became irrelevant. He could not take food himself without caregiver's support for last 3 years. All his symptoms have been gradually progressing and reaching to such an extent that he became bed bound. There was no significant or relevant disease before the development of this disorder. His birth history was uneventful. The patient comes from a lower middle class family. He took alcohol occasionally but his mother could not mention the duration of his alcohol intake, used to take illicit drug whose name and duration of intake could not mentioned by his attendants. The alcoholism and substance abuse was preceded by the ailment. He completed higher secondary level of

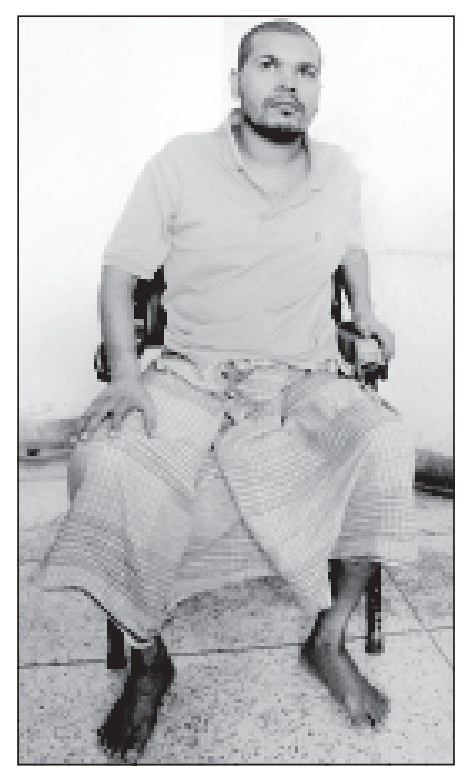

Fig.1: Wheelchair bound patient of DRPLA. education and could not complete his graduation due to this illness. His father and mother are alive with good health. There was no parental consanguinity of marriage. He has one brother and one sister; both are younger to him and are in good health.

On general examination he was found apathic, with good body built, well nourished, poorly dressed and awkwardly postured. His blood pressure was 110/90 $\mathrm{mm}$ of Hg, pulse-70/min, respiration rate $16 / \mathrm{min}$. There was no organomegaly. No other abnormality was found on general examination. K.F. ring was absent. Examination of higher cerebral function revealed incoherent, irrelevant and incomprehensible speech. MMSE score was 0 . All the cranial nerves including fundoscopic examination were normal. Regarding motor system examination; bulk of the muscles was normal, no involuntary movement or tremor was noticed, tone was increased in the form of rigidity, muscle power was MRC grade 4 in four limbs and all the deep tendon reflexes were exaggerated, Hoffman sign was positive with bilateral extensor plantar response. Palmomental reflex and glabellar tap were present but other primitive reflexes were absent. Patient could not stand or walk without support. Co-ordination and sensory examination could not be done as he was unable to follow command properly. Other systems examination revealed no abnormality.

We diagnose the case as DRPLA on clinical basis by excluding some other differentials through clinical ground and available investigations. In the neurology department of BSMMU the patient was treated with Clonazepam 2mg daily and vitamin E capsule 400mg daily for six months. Six month latter (on July 2010) we admitted the patient again in BSMMU, Dhaka for follow up. This time patient was euphoric, not responding to command verbally but can speak or sing a song at his will. He was seizure free, relatively mute and other features were as before. We added memantine 10mg 12 hourly, Co-dopa 110mg 12 hourly to continue for indefinite period. This time psychiatric evaluation was done. The psychiatrist was also agreed with the diagnosis and advised to continue the ongoing treatment as the patient was not aggressive. We advised the attendant follow up visits every 6 (six) months. 
The laboratory investigation reports are summarized in the table below:

\begin{tabular}{|c|c|c|c|c|}
\hline \multicolumn{2}{|c|}{ Sl. No } & \multicolumn{2}{|c|}{ Name of investigation } & \multirow[t]{2}{*}{ Date Result/comment } \\
\hline 1 & Urine $\mathrm{R} / \mathrm{M} / \mathrm{E}$ & 6.01 .10 & Protein-trace. & \\
\hline 2 & TC of WBC & 7.01 .10 & $11000 / \mathrm{cmm}$ & \\
\hline 3 & DC of WBC & 7.01 .10 & Neutrophil-66\%, Lymp & cyte-24\%, Monocyte-04\%, Eosinophil-06\%. \\
\hline 4 & ESR & 7.01 .10 & $10 \mathrm{~mm}$ in $1 \mathrm{st}$ hour. & \\
\hline 5 & Haemoglobin & 7.01 .10 & $14 \mathrm{~g} / \mathrm{dl}$ & \\
\hline & PBF & 7.01 .10 & Unremarkable. & \\
\hline 6 & Chest X-ray & 7.01.10 & Unremarkable. & \\
\hline 7 & Random blood sugar & 7.01 .10 & $5.4 \mathrm{mmol} / \mathrm{L}$ & \\
\hline 8 & S. creatinine & 7.01 .10 & $0.7 \mathrm{mg} / \mathrm{dl}$ & \\
\hline 9 & S. bilirubin & 7.01 .10 & $0.8 \mathrm{mg} / \mathrm{dl}$ & \\
\hline 10 & S. ALT & 7.01 .10 & $26 \mathrm{U} / \mathrm{L}$ & \\
\hline 11 & S. calcium & 7.01 .10 & $8.8 \mathrm{mg} / \mathrm{dl}$ & \\
\hline 12 & S. electrolyte & 7.01 .10 & Na-137 mmol/L, K-4.4 & $\mathrm{mol} / \mathrm{L}, \mathrm{Cl}-99 \mathrm{mmol} / \mathrm{L}, \mathrm{TCO}_{2}-21 \mathrm{mmol} / \mathrm{L}$ \\
\hline 13 & VDRL & 7.01 .10 & Non reactive. & \\
\hline 14 & $\mathrm{TSH}$ & 7.01 .10 & $0.29 \mathrm{mIU} / \mathrm{L}$ & \\
\hline 15 & Vitamin $\mathrm{B}_{12}$ Assay & 7.01 .10 & $430 \mathrm{pgm} / \mathrm{ml}$ & \\
\hline 16 & Anti-HIV (1and 2) & 9.01 .10 & Negative & \\
\hline 17 & ECG & 9.01 .10 & Normal & \\
\hline 18 & EEG & 11.11.09 & Normal. & \\
\hline 19 & CT scan of brain & 10.11 .09 & Generalized cerebral co & cal atrophy of brain with ventriculomegaly. \\
\hline 20 & MRI of brain & 10.01 .10 & Marked degenerative atr & hy of the whole brain with compensatory ventriculomegaly. \\
\hline 21 & USG of abdomen & 25.01 .10 & Normal study & \\
\hline 22 & CSF & 2.2 .10 & $\begin{array}{l}\text { Cytology-TC-2/cmm. } 1 \\
\text { stain and AFB stain- neg }\end{array}$ & $\begin{array}{l}\text { \% lymphocyte.Protein-40mg/dl. Sugar-73.26mg/dl.Gram } \\
\text { ive.Culture and sensitivity-no growth.VDRL-non reactive. }\end{array}$ \\
\hline
\end{tabular}

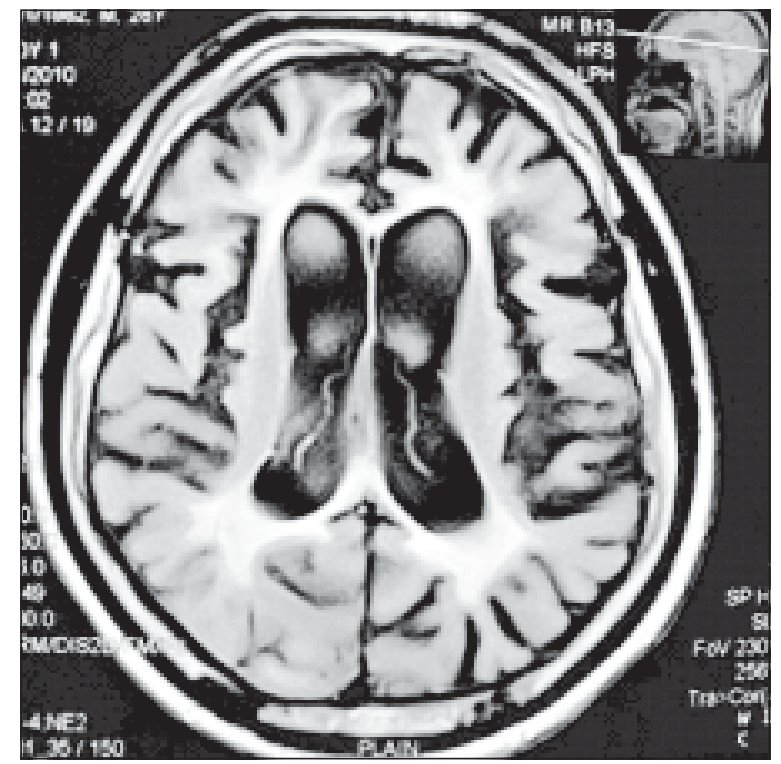

Fig.2: FLAIR axial image of Brain MRI showing gross cerebral atrophy with compensatory lateral ventricular dilatations and periventricular white matter changes.

\section{Discussion:}

Our patient developed a picture of severe ataxia, spastic quadriparesis, dystonia in the form of abnormal posture, myoclonic epilepsy, rigidity, dementia, and psychosis. The MRIs showed a marked degenerative atrophy of the brain with evidence of demyelination. Previous MRI studies in DRPLA showed atrophy of the cerebral cortex, cerebellum, brainstem and in some instances, white matter signal alterations in T2 and fluid-attenuated inversion recovery sequences ${ }^{14-16}$. White matter involvement was not uncommon in a number of autopsy specimens of Japanese and non-Japanese patients with DRPLA ${ }^{16-19}$ Our case highlights the fact that structures other than brainstem and cerebellum may play an important role in disease progression in some patients with DRPLA.

No test for excluding hereditary metabolic diseases of nervous system could be done due to non-availability of tests in our country and patient's financial constraints. So we have to exclude some differential diagnosis on the basis of clinical features and available investigations. We considered presenile dementia of Alzheimer type, 
Huntingtons disease (HD), Creutzfeldt-Jakob disease (CJD), Frontotemporal dementia (FTD), lewy body dementia (LBD), alcoholic dementia, postencephalitic syndrome, metachromatic leucodystrophy (MLD), Niemann-Pick disease, Sialodosis, â-mannosidosis, juvenile and adult onset Sandhoff disease and Tay-Sachs disease as our differential diagnoses. Our patient had seizures, gait disturbance and incoordination at the onset or very early in the course of the illness. According to NINCDS-ADRDA criteria for the diagnosis of alzheimer's disease (AD) these features made the diagnosis of AD unlikely. ${ }^{20}$ Symptoms of HD commonly become noticeable between the ages of 35 and 44 years. The most characteristic initial physical symptoms are chorea. In HD suicidal thoughts and suicide attempts are more common than in the general population. ${ }^{21}$ Muscle atrophy, cardiac failure, impaired glucose tolerance, weight loss, osteoporosis and testicular atrophy usually found in HD. ${ }^{22}$ These findings were inconsistent with our case. The constellation of dementia, myoclonus, and periodic electrical bursts in EEG, an afebrile middle aged patient generally indicates CJD. There should be a history of accidental transmission of CJD. Death usually occurs within 5 years of onset. ${ }^{23}$ EEG was normal in our patient. In FTD significant impairment of frontal lobe tests in the absence of severe amnesia, aphasia, or perceptuospatial disorder; predominant frontal and/or anterior temporal abnormality is frequently present. ${ }^{24}$ But our patient had severe generalized brain atrophy. In LBD there is usually fluctuating cognition with pronounced variations in attention and alertness, recurrent visual hallucinations which are typically well-formed and detailed, repeated falls, syncope, transient loss of consciousness, systematized delusions and hallucinations in other modalities ${ }^{25}$ which are lacking in our patient. Alcoholic dementia is a form of dementia caused by long-term or excessive drinking. The front part of the brain is mostly affected, resulting in poor judgment, difficulty in making decisions, and lack of insight. Long-time alcohol abuse can often lead to poor nutritional problems causing parts of the brain to be damaged by vitamin deficiencies. These problems could also cause personality changes in some people. ${ }^{26}$ Because these warning signs are so similar, alcohol dementia can be difficult to diagnose. Our patient was an occasional drunker and he had generalized atrophy of brain. He had some additional features like seizure, psychosis and parkinsonian features. In his third decade of life with all other features, it was unlikely to be an alcoholic dementia. In postencephalitic dementia there should be a history of encephalitis followed by dementia. Symptoms of the adult form of MLD are- onset after 16 years, mental deterioration, impaired concentration, depression, psychiatric disturbances, ataxia, tremor, dementia, reduced muscle tone, quadriplegia, leukodystrophy, megacolon, muscle wasting, muscle weakness, developmental delay and progressive vision loss. But our patient had neither visual loss, nor tremor, or muscle wasting. In addition our case had no megacolon, or developmental delay. He had epilepsy. So it may not be a case of metachromatic leukodystrophy. Dystonia, splenomegaly, hepatomegaly, dementia, seizures, slurred and irregular speech, cataplexy, tremors, vertical supranuclear gaze palsy and ataxia are the usual features of Niemann-Pick disease ${ }^{27}$. Our case had no organomegaly, cataplexy, tremors, vertical supranuclear gaze palsy. Characteristic features of juvenile onset Sialodosis, are: dysostosis multiplex, cherry-red spots on macula, decreased visual activity, myoclonus and angiokeratomas ${ }^{28,29}$. Most of the features were lacking in our patient. Severe psychomotor retardation, bone deformities, gargoylism, recurrent skin and respiratory infections indicate â-mannosidosis ${ }^{30}$. Sandhoff disease symptoms are clinically indeterminable from Tay-Sachs Disease. Main features of these diseases are cognitive impairment, incoordination of muscle and the characteristic red spots in the retina. The adult form of the disease, however, is sometimes milder and may only lead to muscle weakness that impairs walking or the ability to get out of bed ${ }^{31}$. These features are not consistent with our case.

\section{Treatment:}

No information is available about the treatment of DRPLA, the clinician should be guided by the nature and severity of symptoms ${ }^{32}$. Treatment is only symptomatic.

\section{Limitations:}

In Bangladesh we have no available facilities for the genetic analysis of this kind of disease. The patient also had no family history of such disease. So we are not confirmed about the diagnosis of the case. For confirmation further evaluation can be done.

\section{Conclusion:}

Sporadically mutated cases of autosomal dominant diseases are difficult to diagnose in the absence of facilities for genetic analysis. DRPLA may be found in non Japanese asian people if carefully searched. It is a progressive disease with no curative treatment available at present. Treatment should be symptomatic. Proper 
nutrition, hygiene, regular physiotherapy, nursing and counseling are essential part of management of this type of patient.

\section{References:}

1. Ikeuchi T, Koide R, Tanaka H, Onodera O, Igarashi S, Takahashi H, et al: Dentatorubral-pallidoluysian atrophy: clinical features are closely related to unstable expansions of trinucleotide (CAG) repeat. Ann Neurol 1995; 37:769-75.

2. Koide R, Ikeuchi T, Tanaka H, Onodera O, Igarashi S, Endo $\mathrm{K}$, et al: Unstable expansion of CAG repeat in hereditary dentatorubral-pallidoluysian atrophy (DRPLA). Nature Genet 1994; 6: 9-13.

3. Yazawa I,_Nukina N, Hashida H, Goto J, Yamada M, Kanazawa I. “Abnormal Gene Product Identified in Hereditary DRPLA Brain”. Nat Genet 1995;10 (1): 99-103.

4. Tsuji S. "Dentatorubral-pallidoluysian atrophy: Clinical features and molecular genetics". Adv Neurol 1999;79: 399409.

5. Inatsuki G, Kumagai K, Naito H. Geographical distribution of origins of DRPLA family in Japan, and prevalence of DRPLA in Niigata prefecture [Japanese]. Seishin Igaku 1990; 32:1135-8.

6. Naito H, Oyanagi S. "Familial myoclonus epilepsy and choreoathetosis: hereditary dentatorubral-pallidoluysian atrophy”. Neurology 1982;32 (8): 798-807.

7. Yamada M, Sato T, Tsuji S, Takahashi H. "CAG repeat disorder models and human neuropathology: similarities and differences”. Acta Neuropathol 2008;115 (1): 71-86.

8. Naito H, Oyanagi S. Familial myoclonus epilepsy and choreoathetosis: hereditary dentatorubral-pallidoluysian atrophy. Neurology 1982; 32:789-817

9. Takahashi H, Ohama E, Naito H, Takeda S, Nakashima S, Makifuchi T. Hereditary dentatorubral-pallidoluysian atrophy: clinical and pathological variants in a family. Neurology 1988; 38:1065-70.

10. Morita M, Naito H: Clinical psychopathology of dentatorubropallidoluysian atrophy [Japanese]. Seishin Igaku 1986; 28:1027-35.

11. Naito H, Ohama E, Nagai H, Wakabayashi M, Morita M, Ikuta F. A family of dentato-rubro-pallido-Luysian atrophy including cases with schizophrenic symptoms.Seishin Shinkeigaku Zasshi 1987;89(2):144-58.

12. Adachi N, Onuma T, Akashi T,_Arima K, Asada T, Kato M et al: Four cases of progressive myoclonus epilepsy with paranoid state (Japanese). Seishin Igaku 1992; 34:745-50.

13. Neurogenetics Unit NHNN/ION User Manual 2007-2008 h t t p : / / w w w. cm g s.org / Lab \% 20 Directory / London_InstituteofNeurology\%202007_2008.doc - Cached

14. Koide R, Onodera O, Ikeuchi T, Kondo R, Tanaka H, Tokiguchi S, et al. Atrophy of the cerebellum and brainstem in dentatorubral pallidoluysian atrophy: influence of CAG repeat size on MRI findings. Neurology. 1997;49:1605-12.

15. Yoshii F, Tomisayu H, Shinohara Y. Fluid attenuation inversion recovery (FLAIR) images of dentatorubropallidoluysian atrophy: case report. J Neurol Neurosurg Psychiatry. 1998;65:396-9.
16. Uyama E, Kondo I, Uchino M,Fukushima T, Murayama N, Kuwano A et al. Dentatorubral-pallidoluysian atrophy (DRPLA): clinical, genetic, and neuroradiologic studies in a family. J Neurol Sci. 1995;130:146-53.

17. Burke JR, Wingfield MS, Lewis KE, Roses AD, Lee JE, Hulette C, et al. The Haw River syndrome: dentatorubropallidoluysian atrophy (DRPLA) in an AfricanAmerican family. Nat Genet. 1994;7:521-4.

18. Becher MW, Rubinsztein DC, Lego J, Wagster MV, Stine OC, Ranen NG, et al. Dentatorubral and pallidoluysian atrophy (DRPLA): clinical and neuropathological findings in genetically confirmed North American and European pedigrees. Mov Disord. 1997;12:519-30.

19. Farmer TW, Wingfield MS, Lynch SA, Vogel S, Hulette C, Katchinoff B, et al. Ataxia, chorea, seizures and dementia: pathologic features of a newly defined familial disorder. Arch Neurol. 1989;46:774-9.

20. Galton CJ, Patterson K, Xuereb JH, Hodges JR. Atypical and typical presentations of Alzheimer's disease: a clinical, neuropsychological, neuroimaging and pathological study of 13 cases. Brain 2000;123: 484-98.

21. Walker FO. “Huntington's disease”. Lancet 2007;369 (9557): 218.

22. van der Burg JM, Björkqvist M, Brundin P. Beyond the brain: widespread pathology in Huntington's disease. Lancet Neurol 2009;8(8):765-74.

23. Ropper AH, Brown RH, editors. Adams and Victor's principles of neurology, $8^{\text {th }}$ ed. New York: The MacGraw-Hill Companies; 2005.

24. Cummings JL, Trimble MR. Concise Guide to Neuropsychiatry and Behavioral Neurology, 2nd ed. Washington, DC: American Psychiatric Publishing; 2002.

25. Moroney JT, Bagiella E, Desmond DW, Hachinski VC, Mölsä PK, Gustafson L et al. Meta-analysis of the Hachinski Ischemic Score in pathologically verified dementias. Neurology 1997; 49: 1096-1105.

26. Kapaki, Elissavet. "Alcoholic dementia: myth or reality?”, Annals of General Psychiatry, 28 February 2006.

27. Stanley CA, Bennett MJ. Defects of metabolism in lipids. In: Kliegman RM, Behrman RE, Jenson HB, Stanton BF, eds. Nelson Textbook of Pediatrics. 18th ed. Philadelphia, Pa: Saunders Elsevier; 2007:chap 86.

28. Meikle PJ, Hopwood JJ, Clague AE, Carey WF. Prevalence of Lysosomal Storage Disorders. JAMA 1999; 281: 249-54.

29. Thomas G. "Disorders of Glycoprotein Degradation: Mannosidosis, -Mannosidosis, Fucosidosis, and Sialidosis.” The Metabolic and Molecular Bases of Inherited Disease, 8th Edition Online. McGraw-Hill. September 2004.

30. Kleijer Wj, Hu P, Thoomes R, Boer M, Huijmans Jg, Blom $\mathrm{W}$, at el. "Beta-mannosidase deficiency: heterogeneous manifestation in the first female patient and her brother". Journal of inherited metabolic disease 1990;13 (6): 867-72.

31. Medical Books Excerpts. Lippincott Williams \& Wilkin. 2008.

32. Jankovic J, Shannon KM. Movement disorders. In: Bradley WG, Daroff RB, Fenichel GM, Jankovic J, editors. Neurology in clinical practice. $5^{\text {th }}$ ed. Philadelphia: Butterworth Heimenann Elsevier; 2008.p.2108. 